\title{
Phylogenetic analysis of the ballistosporous anamorphic genera Udeniomyces and Bullera, and related basidiomycetous yeasts, based on 185 rDNA sequence
}

\author{
Sung-Oui Suht and Takashi Nakase
}

Author for correspondence: T. Nakase. Tel: +81484621111 ext. 5111. Fax: +81484624617.

Japan Collection of Microorganisms, The Institute of Physical and Chemical Research (RIKEN), Wako-shi, Saitama 351-01, Japan

\begin{abstract}
The small subunit nuclear ribosomal DNA (18S rDNA) sequence was determined for twelve species of basidiomycetous anamorphic yeasts, i.e. three species of Udeniomyces, seven species of Bullera, Cryptococcus albidus and Phaffia rhodozyma. For phylogenetic analysis, these sequences were aligned with published sequences for 36 other fungal species. Molecular phylogenetic analysis of maximum likelihood and parsimony showed that the 44 species of basidiomycetes analysed were divided into three major lineages. The ballistosporous yeast genera Udeniomyces and Bullera were clearly separated. On the phylogenetic tree, Udeniomyces megalosporus, $U$. puniceus and $U$. piricola showed a very close relationship with one another, and composed a lineage with Mrakia frigida, P. rhodozyma and Cystofilobasidium capitatum at high bootstrap confidence level. On the other hand, eight species of Bullera made lineages with selected species of Tremella (Tremellaceae), Filobasidium and Filobasidiella (Filobasidiaceae), Cryptococcus albidus and Trichosporon cutaneum. The molecular phylogeny deduced from the 18S rDNA sequence showed a possibility of heterogeneity among the species of Bullera at the generic level.
\end{abstract}

Keywords: basidiomycetes, ballistosporous yeasts, Bullera, Udeniomyces, $18 \mathrm{~S}$ rDNA

\section{INTRODUCTION}

Since the establishment of the genus Bullera (Derx, 1930), the symmetrical (rotationally symmetrical) ballistospores and whitish- to pale-coloured colonies have been considered to be important criteria for distinguishing this genus from the genus Sporobolomyces, whose ballistospores ate asymmetrical (bilaterally symmetrical) and whose colonies are deeply pigmented (Lodder \& Kreger-van Rij, 1952). Chemotaxonomically, the genus Bullera has been characterized as containing Q-10 as the major ubiquinone and xylose in the cells (Nakase et al., 1993a). Nakase $(1987,1989)$ divided the species of Bullera into two

\footnotetext{
+Present address: Deep-sea Micro-organisms Research Group, Japan Marine Science and Technology Center, Yokosuka, Kanagawa 237, Japan. The nucleotide sequence data reported in this paper will appear in the GSDB, DDBJ, EMBL and NCBI nucleotide sequence databases with the following accession numbers: D31648 (Bullera crocea), D31649 (B. dendrophila), D31650 (B. globospora), D31651 (B. miyagiana), D31652 (B. oryzae), D31654 (B. variabilis), D31655 (Cryptococcus albidus), D31656 (Phaffia rhodozyma), D31657 (Udeniomyces megalosporus), D31658 (U. puniceus), D31659 (U. piricola), and D31660 (B. pseudoalba).
}

groups, a group of typical Bullera and the piricola group, based on the morphology of ballistospores and the colour of colonies, and suggested that the piricola group represented a different genus from Bullera. Typical Bullera species produce symmetrical ballistospores and palecoloured or orange colonies. The piricola group comprises species which produce large asymmetrical ballistospores and pinkish-white to pale pink colonies. Later, a new genus Udeniomyces was proposed in the Cryptococcaceae for the piricola group of Bullera (Nakase \& Takematsu, 1992).

Nakase et al. (1993b) determined the partial sequence (about $170 \mathrm{bp}$ ) of $18 \mathrm{~S}$ ribosomal RNA of 46 species of ballistosporous yeasts, and found that the piricola group of Bullera (=Udeniomyces) differed from the typical Bullera species based on the comparison of these sequence data.

In studying the phylogeny of fungi, the $18 \mathrm{~S}$ rRNA gene (rDNA) sequence has been considered to be a useful criterion, and recently complete or almost complete sequences of $18 \mathrm{~S}$ rDNA of several fungi have been 
reported (e.g. Berbee \& Taylor, 1992a, b, 1993; Bruns et al., 1992; Hendriks et al., 1989, 1991a, b, 1992; Nishida \& Sugiyama, 1993; Suh \& Sugiyama, 1993; Swann \& Taylor, 1993; Van de Peer et al., 1992; Wilmotte et al., 1993). In basidiomycetous yeasts, however, the complete or almost complete $18 \mathrm{~S}$ rDNA sequence from only a few selected species has been reported (Berbee \& Taylor, 1993; Suh \& Sugiyama, 1993; Swann \& Taylor, 1993; Van de Peer et al., 1992; Wilmotte et al., 1993).

In this paper, we report the nuclear $18 \mathrm{~S}$ rDNA of twelve basidiomycetous anamorphic yeast species, i.e. three species of Udeniomyces, seven species of Bullera, Cryptococcus albidus and Phaffia rbodozyma in an attempt to deduce the phylogenetic relationships of these species and to clarify their classification in higher fungi.

\section{METHODS}

Yeast strains. The following yeast strains were used for sequencing: Bullera crocea JCM 2961 ${ }^{\mathrm{T}}$ (= CBS 6714); B. dendrophila JCM $5357^{\mathrm{T}}$ (= CBS 6704); B. globospora JCM $2957^{\mathrm{T}}$ (=CBS 6981);B. miyagiana JCM 7536 ${ }^{\mathbf{T}} ;$ B. oryzae JCM $5281^{\mathrm{T}}$ (= CBS 7194); B. pseudoalba JCM 5290 (= IFO 10792); B. variabilis JCM 5275 (= CBS 7347); Cryptococcus albidus JCM $2334^{\mathrm{T}}$ (= CBS 142); Phaffia rbodozyma JCM 9042 ${ }^{\mathrm{T}}$ (= IFO 10129); Udeniomyces megalosporus JCM 5269 (= CBS 7236); $U$. piricola JCM $2958^{\mathrm{T}}$ (= CBS 6754); U. puniceus JCM $1535^{\mathrm{T}}$ (= A J 4764). Strains with a superscript $T$ are derived from the type.

PCR and sequencing. The yeasts were grown in YM broth at $17^{\circ} \mathrm{C}$ or $25^{\circ} \mathrm{C}$. DNA was obtained from cells broken by sonication. The gene of the $18 \mathrm{~S}$ rRNA coding region was amplified by polymerase chain reaction (PCR) (Saiki et al., 1988) with the primers P1 5'-ATCTGGTTGATCCTGCCAGT-3' and P2 5'-GATCCTTCCGCAGGTTCACC-3' as described by Nishida \& Sugiyama (1993). PCR products were purified by agarose gel electrophoresis, and sequenced with Sequenase v. 2.0 (US Biochemical).

Phylogenetic analysis. We sequenced the $18 \mathrm{~S}$ rDNA of the 12 yeast species mentioned above and added known sequence data for 36 additional fungal species for analysis. The published sequence data used in this study were obtained from the nucleotide sequence libraries (EMBL, GenBank, and DDBJ). All sequences were aligned using the multialignment program Clustal v (Higgins et al., 1992; UNIX version). The DNAML program in the PHYLIP 3.5c package (Felsenstein, 1993) was used for maximum likelihood analysis (Felsenstein, 1981). From the parsimony analysis, a bootstrap $50 \%$ majority consensus tree was constructed by PAUP 3.0s (Swofford, 1991) with bootstrap analysis of 100 random resamplings.

\section{RESULTS AND DISCUSSION}

\section{Phylogenetic relationships among the basidiomycetes based on 185 rDNA sequence data}

As the result of sequencing, nucleotides of about 1750 bases were determined for each strain from the PCR amplification product of $18 \mathrm{~S} \mathrm{rDNA}$. The sequence data were well aligned for all 48 fungi, including 36 sets of published data, and phylogenetic trees (Fig. 1) were constructed using the ascomycetes Saccharomyces cerevisiae, Kluyveromyces lactis, Candida albicans and Neurospora crassa as an outgroup.
The 44 species of basidiomycetes used in this analysis were divided into three major lineages described as groups 1, 2, and 3 in the maximum likelihood tree (Fig. 1a). The results showed good agreement with those of several reports on fungal evolution (e.g. Bruns $e$ t al., 1992; Suh \& Sugiyama, 1993; Swann \& Taylor, 1993; Wilmotte et al., 1993).

The first major lineage (group 1) in the basidiomycetes included the smut-like, teliospore-forming yeasts (Leucosporidium scottii, Sporidiobolus jobnsonii, Rhodosporidium toruloides) and the related yeasts Sporobolomyces roseus and Erythrobasidium hasegawianum. The rust fungi Cronartium ribicola and Peridermium barknessii were also included in this lineage. The second major lineage (group 2) was composed of the smut fungi (Ustilaginales), represented by Ustilago maydis, $U$. bordei and Tilletia caries. The third major lineage (group 3) could be divided into four sub-groups (3a, b, c, and d; Fig. 1a) which were well supported statistically at high bootstrap levels of 96$100 \%$ (Fig. 1b). The Dacrymycetales, represented by Dacrymyces chrysospermus, D. stillatus, Calocera cornea and Heterotextus alpinus, made up group 3a. Group 3b was composed of the 'teliospore-forming' filobasidiaceous yeasts Mrakia frigida and Cystofilobasidium capitatum, together with species of the anamorphic yeast genera Udeniomyces and Phaffia. Selected species of homobasidiomycetes and Auriculariales were included in group 3c. The Filobasidiaceae, represented by Filobasidium floriforme and Filobasidiella neoformans, and the Tremellaceae, represented by Tremella foliacea, $T$. globospora and T. moriformis composed group 3d together with Bullera spp., Trichosporum cutaneum and Cryptococcus albidus. The three major lineages in basidiomycetes were also found in the tree by the neighbour-joining method (tree not shown). Groups 2 and 3 were not well separated in the most parsimonious consensus tree (Fig. 1b) because the bootstrap confidence level was low $(<50 \%)$.

Most of the basidiomycetous yeasts were included in groups 1 and 3. The teleomorphic yeast genera of group 1, Leucosporidium, Rhodosporidium, Sporidiobolus and Erythrobasidium, are characterized by having simple pores and no xylose in the cells (Table 1). In contrast, genera of group 3, Mrakia, Cystofilobasidium, Filobasidiella, Filobasidium and Tremella (with a yeast phase), have dolipores and xylose in the cells (Table 1). The basidiomycetous anamorphic yeast species, Sporobolomyces roseus, Bullera spp., Cryptococcus albidus and Trichosporon cutaneum, were also located in groups 1 and 3 of Fig. 1(a), and they also correlated well with the presence or absence of xylose in the cells. The value of septal pore ultrastructure and cellular xylose as taxonomic characters in basidiomycetous yeasts has been discussed based on the comparison of $18 \mathrm{~S}$ rDNA sequence (Suh \& Sugiyama, 1993) or $18 \mathrm{~S}$ and $26 \mathrm{~S}$ rRNA partial sequence (Guého et al., 1989; Nakase et al., 1993b). Walker \& Doolittle $(1982,1983)$ and Blanz \& Unseld (1987) concluded, from 5S rRNA sequence comparisons, that septal pore structures were of great value as a taxonomic tool in basidiomycetes. The molecular phylogeny of this study strongly supported the results of the studies mentioned above. 
(a)

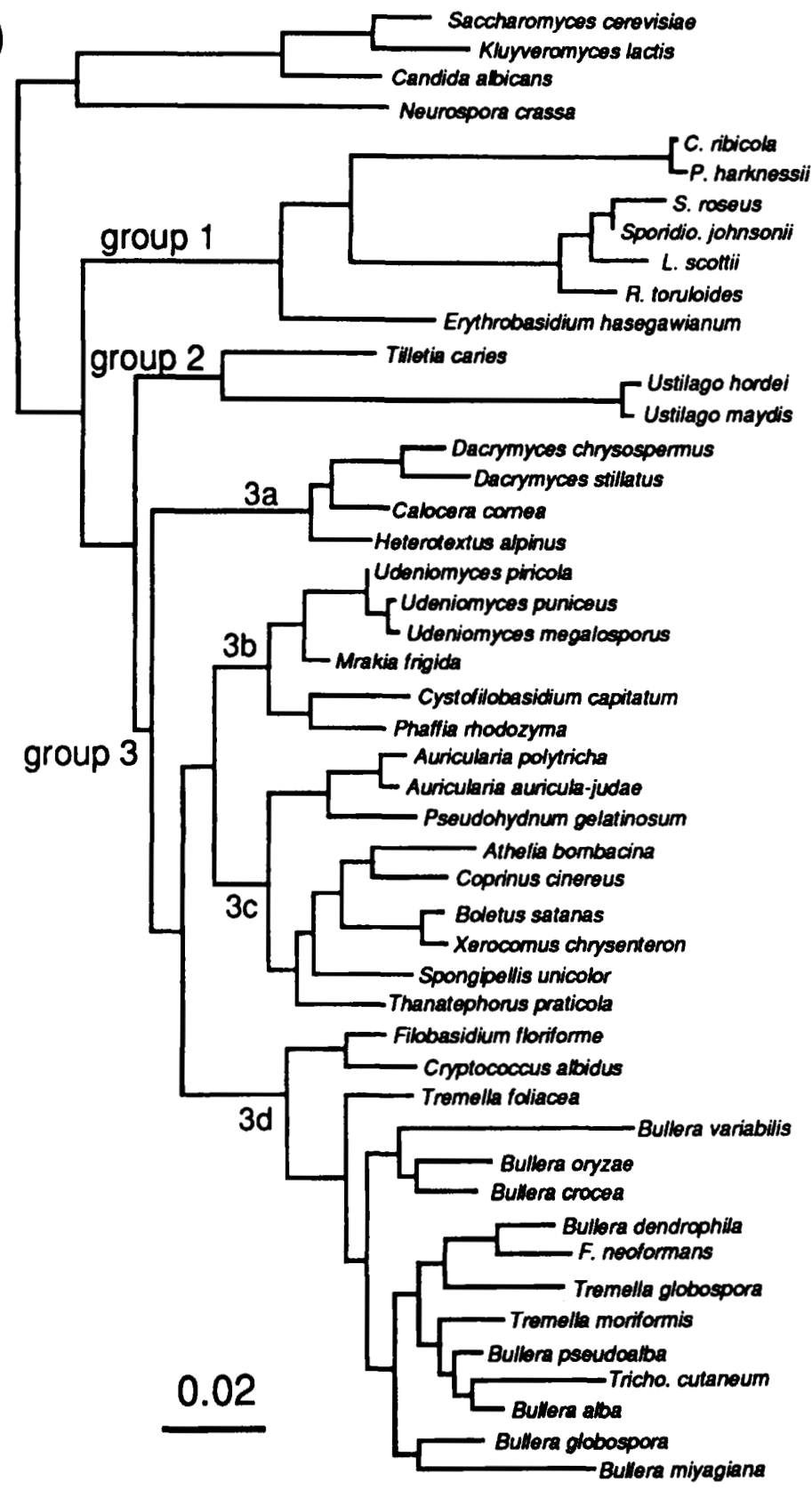

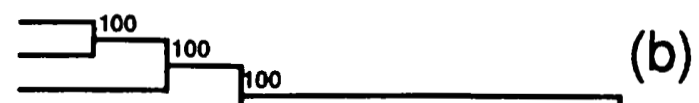

(b)

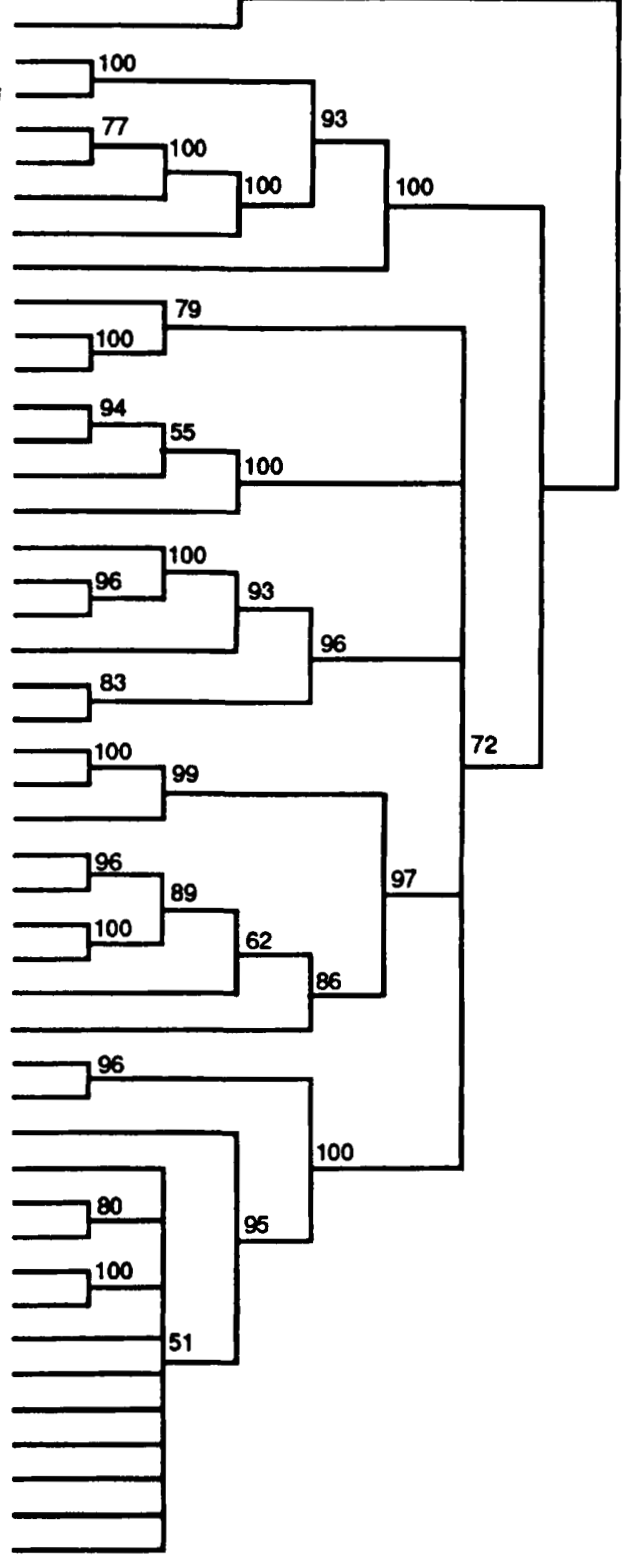

Fig. 1. Phylogenetic relationships of basidiomycetes determined from 185 rDNA sequence. Tree (a) is the result of searching for the best tree by the maximum likelihood method (Felsenstein, 1981) using the DNAML program of the PHYLIP $3.5 \mathrm{c}$ package (Felsenstein, 1993). Tree (b) is the result of parsimony analysis (bootstrap $50 \%$ majority consensus tree) by PAUP 3.0s (Swofford, 1991). Each number in tree (b) indicates the percentage of bootstrap samplings supporting the internal branches.

Phylogeny among the ballistosporous yeasts Bullera and Udeniomyces, and related basidiomycetous yeast genera

Nakase \& Takematsu (1992) proposed a new genus, Udeniomyces, in the Cryptococcaceae for the piricola group of Bullera, which produce large asymmetrical ballistospores and pinkish-white to pale pink colonies. The typical Bullera species produce symmetrical ballistospores and pale-coloured or orange colonies. The genus Udenio- myces comprised three species, Udeniomyces piricola (=Bullera piricola; the type species), $U$. puniceus $(=B$. punicea) and $U$. megalosporus $(=B$. megalospora), which were transferred from Bullera.

Nakase et al. (1993b) determined the partial sequence of 18S ribosomal RNA (positions 1451-1618 in Saccharomyces cerevisiae) of 46 species of ballistosporous yeasts and found that the piricola group of Bullera (=Udeniomyces) differed from the typical Bullera species based on the comparison 
Table 1. Taxonomic characteristics of the basidiomycetous yeast genera used in this study

All the data are from the literature (see text for references).

\begin{tabular}{|lcccc|}
\hline Genus & $\begin{array}{c}\text { Xylose } \\
\text { in cell } \\
\text { wall }\end{array}$ & $\begin{array}{c}\text { Septal } \\
\text { pore }\end{array}$ & Ballistospore & $\begin{array}{c}\text { Major } \\
\text { ubiquinone }\end{array}$ \\
\hline Teleomorph & & & & \\
Leucosporidium & - & Simple pore & - & Q-9/Q-10 \\
Rhodosporidium & - & Simple pore & - & Q-9/Q-10 \\
Sporidiobolus & - & Simple pore & + & Q-10 \\
Erytbrobasidium & - & Simple pore & - & Q-10 $\left(\mathrm{H}_{2}\right)$ \\
Cystofilobasidium & + & Dolipore & - & Q-8 \\
Mrakia & + & Dolipore & - & Q-8 \\
Filobasidium & + & Dolipore & - & Q-9/Q-10 \\
Filobasidiella & + & Dolipore & - & Q-10 \\
Tremella & + & Dolipore & - & Q-10 \\
Anamorph & & & & \\
Bullera & + & $? *$ & + & Q-10 \\
Cryptococcus & + & $?$ & - & Q-8/Q-9/Q-10 \\
Phaffia & + & $?$ & - & Q-10 \\
Trichosporon & + & $?$ & - & Q-9/Q-10 \\
Udeniomyces & + & $?$ & + & Q-10 \\
Sporobolomyces & - & $?$ & + & Q-10† \\
\hline
\end{tabular}

* Bulleromyces albidus (teleomorph of Bullera alba) has dolipores.

†One species has Q-10( $\left.\mathrm{H}_{2}\right)$.

of these sequence data. However, in the study of Nakase et al. (1993b), it was not enough to clearly explain their phylogenetic positions, because the sequence data were too short by one molecule (about $10 \%$ of complete $18 \mathrm{~S}$ rRNA sequence) and most of the main lineages of the tree were not supported well statistically.

In the trees based on $18 \mathrm{~S}$ rDNA sequence (Fig. 1), the three species of Udeniomyces, i.e. U. piricola, $U$. puniceus and $U$. megalosporus, made a single branch and were included in group $3 \mathrm{~b}$ with $M$. frigida, $C$. capitatum and $P$. rhodozyma. On the other hand, the species of Bullera were located in group 3d. Eight species of Bullera made up a lineage with $F$. neoformans, Tremella globospora, T. moriformis and Trichosporon cutaneum at the $95 \%$ bootstrap confidence level (Fig. 1b), but they showed a tendency to be heterogeneous at the generic level. Bullera dendrophila was placed on the same branch as Filobasidiella neoformans, and Bullera pseudoalba and $B$. alba showed a relationship with Tremella moriformis. The possibility of heterogeneity in Bullera species was also supported by the results of parsimony (Fig. 1b). The three species of Udeniomyces were closely related to one another based on the evolutionary distance as shown in Table 2. On the other hand, Bullera species were located at positions with varying evolutionary distances. Bullera miyagiana and B. variabilis were the species most distant to each other among eight species of Bullera examined. However, as shown in Fig. 1(b), the relationships between each species of Bullera and other related basidiomycetes species were difficult to clarify as most branches were not supported well statistically.
The molecular phylogeny suggests that the presence or absence of ballistospores is not a rational criterion for the higher taxa in basidiomycetous yeasts, because the ballistosporous yeasts Sporidiobolus, Sporobolomyces, Udeniomyces and Bullera belong to different phylogenetic groups (Fig. 1). However, the morphology of ballistospores may be important in the taxonomy of ballistosporous yeasts at generic or specific level as in the case of Udeniomyces and Bullera.

Boekhout et al. (1991) described the occurrence of sexual reproduction in Bullera alba and proposed a new basidiomycetous teleomorphic genus Bulleromyces. This genus was placed in the Tremellales based on basidial morphology and septal pore ultrastructure. Several authors have postulated a close relationship between the Filobasidiaceae and Tremellaceae (Jülich, 1981; Moore, 1978; Slodki et al., 1966). Oberwinkler (1990) included the Filobasidiaceae as a family of the Tremellales in a study of septal pore ultrastructure. From molecular phylogeny analysis Swann \& Taylor (1993) found that Filobasidiella neoformans and Tremella foliacea made a branch in the most parsimonious tree of $18 \mathrm{~S}$ rDNA sequence. Van de Peer et al. (1992) reported the $18 \mathrm{~S} \mathrm{rDNA}$ sequence of $B$. alba (= Bulleromyces albus) and found that it showed a close relationship with $F$. neoformans of the Filobasidiaceae. In Fig. 1, eight species of Bullera grouped with the species of Tremella (Tremellaceae), Filobasidium and Filobasidiella (Filobasidiaceae), Trichosporon and Cryptococcus. Our results strongly support the close relationship between the families Filobasidiaceae and Tremellaceae. 
Table 2. Evolutionary distance among the species of Bullera and Udeniomyces, and Sporobolomyces roseus

Evolutionary distance is percentage divergence $(/ 100)$ calculated by the CLUSTAL v (Higgins et al., 1992).

\begin{tabular}{|c|c|c|c|c|c|c|c|c|c|c|c|}
\hline Species & 1 & 2 & $\because 3$ & 4 & 5 & 6 & 7 & 8 & 9 & 10 & 11 \\
\hline 1. Bullera alba & - & & & & & & & & & & \\
\hline 2. Bullera crocea & $0 \cdot 0323$ & - & & & & & & & & & \\
\hline 3. Bullera dendrophila & 0.0353 & 0.0429 & - & & & & & & & & \\
\hline 4. Bullera globospora & $0 \cdot 0247$ & 0.0376 & 0.0329 & - & & & & & & & \\
\hline 5. Bullera miyagiana & $0 \cdot 0470$ & 0.0476 & $0 \cdot 0464$ & 0.0447 & - & & & & & & \\
\hline 6. Bullera oryzae & $0 \cdot 0335$ & $0 \cdot 0253$ & 0.0429 & 0.0364 & $0 \cdot 0511$ & - & & & & & \\
\hline 7. Bullera pseudoalba & $0 \cdot 0123$ & 0.0347 & 0.0329 & 0.0282 & $0 \cdot 0488$ & 0.0276 & - & & & & \\
\hline 8. Bullera variabilis & $0 \cdot 0611$ & $0 \cdot 0523$ & $0 \cdot 0623$ & $0 \cdot 0558$ & 0.0705 & $0 \cdot 0564$ & 0.0605 & - & & & \\
\hline 9. Udeniomyces megalosporus & $0 \cdot 0552$ & $0 \cdot 0588$ & 0.0699 & $0 \cdot 0652$ & 0.0799 & 0.0635 & 0.0576 & $0 \cdot 0828$ & - & & \\
\hline 10. Udeniomyces puniceus & 0.0552 & 0.0599 & 0.0711 & 0.0664 & 0.0811 & 0.0646 & 0.0588 & 0.0852 & 0.0047 & - & \\
\hline 11. Udeniomyces piricola & $0 \cdot 0541$ & 0.0599 & 0.0711 & $0 \cdot 0640$ & $0 \cdot 0811$ & 0.0646 & 0.0576 & $0 \cdot 0840$ & $0 \cdot 0024$ & 0.0047 & - \\
\hline 12. Sporobolomyces roseus & $0 \cdot 1146$ & $0 \cdot 1175$ & $0 \cdot 1187$ & $0 \cdot 1199$ & $0 \cdot 1287$ & $0 \cdot 1181$ & $0 \cdot 1193$ & $0 \cdot 1316$ & $0 \cdot 1105$ & $0 \cdot 1110$ & $0 \cdot 1099$ \\
\hline
\end{tabular}

The genera Cystofilobasidium and Mrakia have been distinguished from Rhodosporidium and Leucosporidium mainly by ultrastructural and chemotaxonomic data and have been assigned to the Filobasidiaceae (Oberwinkler et al., 1983; Yamada \& Komagata, 1987). Suh \& Sugiyama (1993) found that Cystofilobasidium capitatum and M. frigida were well separated from $R$. toruloides and $L$. scottii, and showed a relationship with species of the Filobasidiaceae based on $18 \mathrm{~S}$ rDNA sequence comparison. In Fig. 1, C. capitatum and $M$. frigida are located in group 3 with other filobasidiaceous yeasts. However, the trees showed that it may be possible to separate these two genera from other filobasidiaceous yeasts because the branch including Cystofilobasidium and Mrakia (group 3b) makes a lineage with selected species of homobasidiomycetes and Auriculariales (group 3c) and not with other filobasidiaceous yeasts (group 3d). These two genera could be distinguished from other Filobasidiaceae by the formation of teliospores and possession of the Q-8 ubiquinone system.

Weijman \& Rodrigues de Miranda (1988) transferred Phaffia rhodozyma, the single species of the genus, to Cryptococcus based on the monosaccharide composition of whole cell hydrolysates. However, Yamada et al. (1990) advocated retention of the genus Phaffa based on the comparison of $18 \mathrm{~S}$ and $26 \mathrm{~S}$ rRNA partial sequence. As shown in the present study (Fig. 1), P. rhodozyma made a branch with Cystofilobasidium capitatum in group 3b, while Cryptococcus albidus was located in group 3d together with species of Tremella, Filobasidiella, Filobasidium, Bullera and Trichosporon. The same result was obtained from the most parsimonious tree (Fig. 1b). This fact strongly supports the separation of the two genera, Phaffia and Cryptococcus.

In this study, we have discussed the phylogeny of basidiomycetes from $18 \mathrm{~S}$ rDNA sequence data of 44 selected species. Most of our results showed good agreement with those reported by other investigators as mentioned above. However, more sequence data from several classes of basidiomycetes may be needed to discuss clearly the phylogenetic relationships of these taxa. Also, the sequence data of other species of the genus and related ballistosporous yeast taxa, particularly species of Itersonilia and Kockovaella, will be needed to clarify the phylogenetic position of Bullera species, although phylogenetic heterogeneity among species of Bullera has been suggested in the present study.

\section{REFERENCES}

Berbee, M. L. \& Taylor J.W. (1992a). Two ascomycete classes based on fruiting-body characters and ribosomal DNA sequence. Mol Biol Evol 9, 278-284.

Berbee, M. L. \& Taylor, J. W. (1992b). Convergence in ascospore discharge mechanism among pyrenomycete fungi based on $18 \mathrm{~S}$ ribosomal RNA gene sequence. Mol Pbylogenet Evol 1, 59-71.

Berbee, M. L. \& Taylor, J.W. (1993). Dating the evolutionary radiations of the true fungi. Can J Bot 71, 1114-1127.

Blanz, P. A. \& Unseld, M. (1987). Ribosomal RNA as a taxonomic tool in mycology. Stud Mycol 30, 247-258.

Boekhout, T., Fonseca, A. \& Batenburg-van der Vegte, W. H. (1991). Bulleromyces genus novum (Tremellales), a teleomorph for Bullera alba, and the occurrence of mating in Bullera variabilis. Antonie Leeuwenboek 59, 81-93.

Bruns, T. D., Vilgalys, R., Barns, S. M., Gonzales, D., Hibbett, D. S., Lane, D. J., Simon, L., Stickel, S., Szaro, T. M., Weisburg, W. G. \& Sogin, M. L. (1992). Evolutionary relationships within the fungi: analyses of nuclear small subunit rRNA sequences. Mol Pbylogenet Evol 1, 231-241.

Derx, H. G. (1930). Étude sur les Sporobolomycètes. Ann Mycol 28, 1-23.

De Wachter, R., Neefs, J.-M., Goris, A. \& Van de Peer, Y. (1992). The gene coding for small ribosomal subunit RNA in the basidiomycete Ustilago maydis contains a group I intron. Nucleic Acids Res 20, 1251-1257.

Felsenstein, J. (1981). Evolutionary trees from DNA sequences: a maximum likelihood approach. $J$ Mol Evol 17, 368-376.

Felsenstein, J. (1985). Confidence limits on phylogenies: an approach using the bootstrap. Evolution 39, 783-791. 
Felsenstein, J. (1993). PHYLIP (Phylogeny Inference Package) version 3.5c. Distributed by the author. Department of Genetics, University of Washington, Seattle, USA.

Guého, E., Kurtzman, C. P. \& Peterson, S. W. (1989). Evolutionary affinities of heterobasidiomycetous yeast estimated from $18 \mathrm{~S}$ and 25S ribosomal RNA sequence divergence. Syst Appl Microbiol 12, 230-236.

Hendriks, L., Goris, A., Neefs, J.-M., Van de Peer, Y., Neefs, J., Hennebert, G. \& De Wachter, R. (1989). The nucleotide sequence of the small ribosomal subunit RNA of the yeast Candida albicans and the evolutionary position of the fungi among the eukaryotes. Syst Appl Microbiol 12, 223-229.

Hendriks, L., de Baere, R., Van de Peer, Y., Neefs, J., Goris, A. \& De Wachter, R. (1991a). The evolutionary position of the rhodophyte Porphyra umbilicalis and the basidiomycete Leucosporidium scottii among other eukaryotes as deduced from complete sequences of small ribosomal subunit RNA. J Mol Evol 32, 167-177.

Hendriks, L., Goris, A., Van de Peer, Y., Neefs, J., Vancanneyt, M., Kersters, K., Hennebert, G. L. \& De Wachter, R. (1991b). Phylogenetic analysis of five medically important Candida species as deduced on the basis of small ribosomal subunit RNA sequences. $J$ Gen Microbiol 137, 1223-1230.

Hendriks, L., Goris, A., Van de Peer, Y., Neefs, J., Vancanneyt, M., Kersters, K., Berny, J., Hennebert, G. L. \& De Wachter, R. (1992). Phylogenetic relationships among Ascomycetes and Ascomycetelike yeast as deduced from small ribosomal subunit RNA sequences. Syst Appl Microbiol 15, 98-104.

Higgins, D. G., Bleasby, A. J. \& Fuchs, R. (1992). CLUSTAL V: improved software for multiple sequence alignment. CABIOS $\mathbf{8}$, 189-191.

Julich, W. (1981). Higher Taxa of Basidiomycetes. Vaduz Lichtenstein: J. Cramer.

Lodder, J. \& Kreger-van Rij, N. J. W. (1952). The Yeasts, a Taxonomic Study, 1st edn. Amsterdam: North-Holland Publishing Co.

Moore, R. T. (1978). Taxonomic significance of septal ultrastructure with particular reference to the jelly fungi. Mycologia 70, 1007-1024.

Nakase, T. (1987). Isolation and maintenance of ballistosporeforming yeasts. Stud Mycol 30, 375-387.

Nakase, T. (1989). Classification of ballistospore-forming yeasts. Yeast 5, S511-516.

Nakase, T. \& Takematsu, A. (1992). Udeniomyces, a new ballistosporous anamorphic yeast genus in the Cryptococcaceae proposed for three Bullera species which produce large bilaterally symmetrical ballistospores. FEMS Microbiol Lett 100, 497-502.

Nakase, T., Takematsu, A., Hamamoto, M. \& Takashima, M. (1993a). The expanding realm of ballistosporous yeasts. Antonie Leeuwenboek 63, 191-200.

Nakase, T., Takematsu, A. \& Yamada, Y. (1993b). Molecular approaches to the taxonomy of ballistosporous yeasts based on the analysis of the partial nucleotide sequences of $18 \mathrm{~S}$ ribosomal ribonucleic acids. J Gen Appl Microbiol 39, 107-134.

Nishida, H. \& Sugiyama, J. (1993). Phylogenetic relationships among Taphrina, Saitoella and other higher fungi. Mol Biol Evol 10, 431-436.
Oberwinkler, F. (1990). Problems in the systematics of heterobasidiomycetes. In Abstracts of the Fourth International Mycological Congress, p. 43. Edited by A. Reisinger \& A. Bresinsky. Regensburg: University of Regensburg.

Oberwinkler, F., Bandoni, R., Blanz, P. \& Kisimova-Horovitz, L. (1983). Cystofilobasidium: a new genus in the Filobasidiaceae. Syst Appl Microbiol 4, 114-122.

Saiki, R., Gelfand, D. H., Stoffel, S., Scharf, S., Higuchi, R., Horn, G. T., Mullis, K. B. \& Erlich, H. A. (1988). Primer-directed enzymatic amplification of DNA with a thermostable DNA polymerase. Science 239, 487-491.

Slodki, M. E., Wickerham, L. J. \& Bandoni, R. J. (1966). Extracellular heteropolysaccharides from Cryptococcus and Tremella: a possible taxonomic relationship. Can J Microbiol 12, 489-494.

Suh, S. -O. \& Sugiyama, J. (1993). Phylogeny among the basidiomycetous yeasts inferred from small subunit ribosomal DNA sequence. J Gen Microbiol 139, 1595-1598.

Swann, E. C. \& Taylor, J. W. (1993). Higher taxa of Basidiomycetes: an 18S rRNA gene perspective. Mycologia 85, 923-936.

Swofford, D. L. (1991). PAUP: phylogenetic analysis using parsimony, version 3.0s. Champaign, Illinois: Illinois Natural History Survey.

Van de Peer, Y., Hendriks, L., Goris, A., Neefs, J.-M., Vancanneyt, M., Kersters, K., Berny, J.-F., Hennebert, G. L. \& De Wachter, R. (1992). Evolution of basidiomycetous yeasts as deduced from small ribosomal subunit RNA sequences. Syst Appl Microbiol 15, 250-258.

Walker, W. F. \& Doolittle, W. F. (1982). Redividing the basidiomycetes on the basis of $5 \mathrm{~S}$ rRNA nucleotide sequences. Nature $\mathbf{2 9 9}$, 723-724.

Walker, W. F. \& Doolittle, W. F. (1983). 5S rRNA sequences from eight basidiomycetes and fungi imperfecti. Nucleic Acids Res 11, $7625-7630$

Weijman, A. C. M. \& Rodrigues de Miranda, L. (1988). Carbohydrate patterns of Candida, Cryptococcus and Rbodotorula species. Antonie Leeuwenboek 54, 535-543.

Wilmotte, A., Van de Peer, Y., Goris, A., Chapelle, S., De Baere, R., Nelissen, B., Neefs, J.-M., Hennebert, G. L. \& De Wachter, R. (1993). Evolutionary relationships among higher fungi inferred from small ribosomal subunit RNA sequence analysis. Syst Appl Microbiol 16, 436-444.

Yamada, Y. \& Komagata, K. (1987). Mrakia gen. nov., a heterobasidiomycetous yeast genus for the Q8-equipped, selfsporulating organisms which produce a unicellular metabasidium, formerly classified in the genus Leucosporidium. J Gen Appl Microbiol 33, 455-457.

Yamada, Y., Nagahama, T., Kawasaki, H. \& Banno, I. (1990). The phylogenetic relationship of the genera Phaffia Miller, Yoneyama et Soneda and Cryptococcus Kützing emend. Phaff et Spencer (Cryptococcaceae) based on the partial sequences of $18 \mathrm{~S}$ and $26 \mathrm{~S}$ ribosomal ribonucleic acids. J Gen Appl Microbiol 36, 403-414.

Received 31 August 1994; revised 15 December 1994; accepted 18 January 1995. 